\title{
Nutritional Status of Diet Soft Drinks Consumption Among Chilean School Children
}

\author{
Ximena Rodríguez Palleres ${ }^{1 *}$, Gabriella Di Capua Ramírez ${ }^{1}$ and Álvaro \\ Toledo San Martín ${ }^{2}$ \\ ${ }^{1}$ School of Nutrition and Dietetics, Faculty of Health Sciences, Bernardo O'Higgins \\ University, Chile \\ ${ }^{2}$ Department of Mathematics and Physics, Bernardo O'Higgins University, Chile \\ *Corresponding Author: Ximena Rodríguez Palleres, School of Nutrition and \\ Dietetics, Faculty of Health Sciences, Bernardo O'Higgins University, Chile.
}

DOI: 10.31080/ASNH.2020.05.0811

Received: December 29, 2020

Published: January 16, 2021

(C) All rights are reserved by Ximena

Rodríguez Palleres., et al.

\section{Abstract}

Background: The childhood obesity is a public health problem whose main causes are the consumption of processed foods and junk food with a decrease in physical activity.

Objective: The aim of the study was to examine the existence of associations between nutritional status and the consumption of diet soft drinks in school children in Santiago, Chile.

Methods: Cross-sectional study. The sample consisted of 157 school children of both sexes from 6 to 9 years of age of the Renca municipality, Santiago, Chile. To determine the nutritional status, weight, height and waist circumference were evaluated. To describe the consumption of diet soft drinks, a survey prepared for this study was applied.

Results: $57.97 \%$ of school children are overweight and obese according to BMI. Regarding abdominal obesity, 53.51\% presented this condition according to waist circumference. $64.34 \%$ consume diet soft drinks at least one glass a day. Compared to the children who never drink diet soft drinks, the risk of obesity was higher in those who drank 1 glass a day of diet soft drinks (Odds ratio (OR): 1.02 [(IC) 95\%: 0.45-2.32]), and who consumed 2 or more glasses a day of diet soft drinks (Odds ratio (OR): 1.52 [(IC) 95\%: 0.74-3.2] p $=0.258$ ). The risk of abdominal obesity in school children who consumed 1 glass (Odds ratio (OR): 1.3 [(IC) 95\%: 0.58-2.98]) or 2 glasses a day of diet soft drinks (Odds ratio (OR): 1.1 [(IC) 95\%: 0.57-2.4] p = 0.6726) was also higher.

Conclusion: There is a high prevalence of excess malnutrition accompanied by a significant percentage of children who drink diet soft drinks daily. School children who drink diet soft drinks every day are at increased risk of obesity.

Keywords: Nutritional Status; Diet Soft Drinks; Obesity; Abdominal Obesity; School Children; Cardiovascular Risk

\section{Introduction}

In recent decades the prevalence of childhood overweight and obesity have increased rapidly, becoming a major public health problem [1]. In Chile, the prevalence of overweight in adults is $39.8 \%$ and of obesity is $31.2 \%$ [2]. In the Chilean school population, the prevalence of excess malnutrition (overweight and obesity) in Pre-Kindergarten ( 4 years old), Kindergarten ( 5 years old), 1 st grade (6 years old), 5st grade (10 years old) y ninth grade (14 years old) were 50.2\%, 51.3\%, 50.9\%, 60.0\% and 47.6\% respectively [3].

Regarding the consequences of obesity, there is a higher risk of cardiovascular diseases, diabetes, musculoskeletal diseases, respiratory problems, infertility and some types of cancer such as colon, endometrium and breast cancer [4]. Children with obesity are more likely to be overweight and obese in adulthood than children with normal nutritional status [5]. 
The cause of childhood obesity may be are related to changes in lifestyle. One of these changes is the decrease in physical activity, encouraged by the greater use of the computer, television, video games and electronic devices [6]. This lower energy expenditure is accompanied by an increase in the consumption of processed foods, junk food, larger portion sizes, and diets rich in simple sugars present mainly in soft drinks [7].

Soft drinks are characterized by the presence of carbon dioxide (generating the gas), citric acid, malic acid and phosphoric acid, preservatives, colorants, as well as a high sugar content, being of high caloric density [8]. In addition, the soft drinks contain a high amount of sugar. On average $350 \mathrm{ml}$ of soft drink contains 140 to 150 calories and between 35.0 to 37.5 grams of sugar, being of high caloric density food [9].

The consumption of carbonated beverages has increased dramatically in recent decades worldwide, increased from 9.5 gallons per person per year in 1997 to 11.4 gallons per person per year in 2010. Chile is not out of this reality, being the fourth highest consumer worldwide in soft drinks with a yearly per capita consumption of 28.8 gallons in 2010, being surpassed by Mexico who leads the rate of consumption of soft drinks with 31.5 gallons per capita yearly, followed by the United States (31.2 gallons) and in third place is Argentina (30.6 gallons) [7]. In Chile, the consumption of carbonated beverages went from 42.3 gallons to 61.5 gallons per capita between 2002 and 2012 [10].

Among the negative health implications of drinking soft drinks, there is an increased in serum triglyceride levels, risk of type 2 diabetes mellitus, dental caries, and metabolic syndrome [11]. Furthermore, several epidemiological studies have shown positive associations between the consumption of soft drinks and obesity [12]. The adverse effects of consuming soft drinks on the development of obesity could be due to the high sugar content of these beverages, accompanied by a lower power of satiety, in addition to non-compensation of the consumption of calories from sugars by reducing other foods [13].

Diet soft drinks are marketed as a healthier alternative to sugar-sweetened soft drinks, which are carbonated drinks without calories, artificially sweetened in replacement of sugar [14]. Despite this, the consumption of this type of beverage has been associated with some health risks, such as metabolic syndrome and type 2 diabetes in the adult population [15]. However, there are few studies in Chile on the association between the consumption of diet soft drink and obesity in the school population. The objective of this study is to examine the association between nutritional status, cardiovascular risk factors and throughout the consumption of diet soft drink in school children aged 6 to 9 in Santiago, Chile.

\section{Materials and Methods}

The study design is a cross-sectional association study regarding the consumption of diet soft drinks, nutritional status and cardiovascular risk.

The participants were 157 school children from 6 to 9 years of age, of which 92 were boys and 65 girls from a school in the Renca municipality of Santiago, Chile. The inclusion criteria were school children between 6 and 9 years old and who were present at the time of the evaluation, with the exclusion of the students who did not attend classes on the day of the evaluation, or were not in the aforementioned age ranges and presented some metabolic disease according to the health status reported by the parents in the personal interview.

\section{Assessment of nutritional status}

To measure body weight, a SECA 803 model was used, placed on a smooth and flat surface, calibrated at zero. The students had minimal clothing and were barefoot. Once located in the center of the platform, they stood still with the weight evenly distributed on both feet facing forward [16].

Height was measured with a SECA 213 model height rod, placing the students standing barefoot with the head oriented in the Frankfort plane, with the arms on both sides of the trunk, extended and with palms touching the outer side of the thighs, heels together touching the lower end of the vertical surface with the inner edge of the feet at the 45 to 60 degree angle, occipital area, scapular area, back of knees and calves touching vertical surface of height $\operatorname{rod}[16]$.

The Body Mass Index (BMI = Weight in $\mathrm{kg} /$ Height $^{2}$ in $\mathrm{m}$ ) of the school children was obtained and normalized by z-score. To classify children with underweight, normal, overweight and obesity, the cut-off points for the z-scores of the Chilean technical standard were used. The cut-off points used were underweight $\leq-1$; normal $+0,9$ a 0,9 ; overweight $\geq+1 \mathrm{a}+1,9$; obesity $\geq+2$ [17]. 


\section{Evaluation of cardiovascular risk}

To determine the cardiovascular risk of school children, waist circumference was measured using a flexible SECA 201 model tape measure, but not extensible, with a precision of $0.1 \mathrm{~cm}$. The student stood up, identifying the area to be measured at $1 \mathrm{~cm}$ above the upper lateral edge of the iliac crest, making the measurement after normal expiration. The Chilean technical standard was used for classification: Normal $<$ p75; Risk of abdominal obesity $75<\mathrm{p}<90$; Abdominal obesity >p90 [17].

Diet soft drinks consumption survey

This survey was prepared for study, being validated by three nutritionists from the School of Nutrition and Dietetics of the Bernardo O'Higgins University of Chile and later applied in a group of 15 school children between 6 and 9 years old from an educational establishment in the Pedro Aguirre Cerda municipality of Santiago, Chile, obtaining the final instrument.

The consumption of diet soft drinks was defined according to whether the soft drink was "light", "diet" or "zero-calorie". Parents were asked to report their children's consumption of diet soft drinks (never up to 7 times a week) and the number of glasses (each $200 \mathrm{ml}$ glass) they consumed per day. Consequently, we classified the school children who consumed 0 glasses a day, 1 glass a day and 2 or more glasses a day.

\section{Statistical analysis}

Data is displayed as a percentage, median, and standard deviation. Shapiro-Wilk test was used to evaluate normality of data set. Difference between groups were reported accordingly one-way ANOVA or Kruskall-Wallis analysis. Tukey and Dunn tests for multiple comparison were performed respectively. The association between the consumption of soft diet drinks, nutritional status and cardiovascular risk was evaluated by logistic regression analysis, the results are reported as Odds Ratio (OR) respect to the group that does not consume soft diet drinks. The dependence of soft diet drinks consumption on nutritional status and cardiovascular risk was evaluated using the $\mathrm{Chi}^{2}$ test. Significance is reported at $95 \%$ confidence with p-value $<0.05$. RStudio version 1.0.136 was used for statistical analyzes.
Ethical aspects

This research was carried out in accordance with the Declaration of Helsinki. Parents and/or guardians signed an informed consent form. The study was approved by the Ethics Committee of the Bernardo O’Higgins University.

\section{Results and Discussion}

General and anthropometric characteristics of the 157 evaluated school children are reported in table 1 . Significant differences in the average value of weight, BMI, z BMI and waist circumference were observed in obese subjects regarding normal nutritional status, which were previously classified according to both, their nutritional status and consuming conduct. No significant difference was found in the parameters evaluated when comparing normal weight subjects in the control group regarding the group that consumes diet soft drinks or between ages. In the group consuming diet soft drinks, a significant difference in the height of obese subjects regarding normal weight was also found.

\begin{tabular}{|c|c|c|c|c|c|}
\hline & \multicolumn{2}{|c|}{ Controls } & \multicolumn{2}{|c|}{ Diet soft drinks } & \multirow[b]{2}{*}{ p-value } \\
\hline & $\begin{array}{l}\text { Normal } \\
(n=26)\end{array}$ & $\begin{array}{l}\text { Obesity } \\
(n=30)\end{array}$ & $\begin{array}{l}\text { Normal } \\
(n=40)\end{array}$ & $\begin{array}{l}\text { Obesity } \\
(n=61)\end{array}$ & \\
\hline $\begin{array}{c}\text { Age } \\
\text { (months) }\end{array}$ & 92.4 (15.8) & $99.0(15.5)$ & $93.8(13.5)$ & $96.3(13.9)$ & 0.305 \\
\hline $\begin{array}{l}\text { Weight } \\
\text { (kg) }\end{array}$ & $25.3(4.8)$ & $37.8(12.8)^{*}$ & $24.8(3.9)$ & $36.8(10.7)^{*+}$ & $<0.001$ \\
\hline $\begin{array}{l}\text { Height } \\
\text { (cm) }\end{array}$ & $125.5(9.1)$ & $129.8(9.3)$ & $125.0(7.2)$ & $130.2(8.7)^{+}$ & 0.007 \\
\hline $\begin{array}{c}\text { BMI }(\mathrm{kg} / \\
\left.\mathrm{mt}^{2}\right)\end{array}$ & $15.9(1.2)$ & $22.0(4.7)^{*}$ & $15.8(1.1)$ & $21.3(3.8)^{*+}$ & $<0.001$ \\
\hline z BMI & $0.1(0.8)$ & $2.3(1.1)^{*}$ & $0.0(0.7)$ & $2.2(0.8)^{*+}$ & $<0.001$ \\
\hline \begin{tabular}{|c|} 
Waist \\
circumfer- \\
ence $(\mathrm{cm})$
\end{tabular} & $58.3(5.6)$ & $72.3(12.2)^{*}$ & $57.5(3.6)$ & $71.7(11.2)^{*+}$ & $<0.001$ \\
\hline \multicolumn{6}{|c|}{$\begin{array}{l}\text { Data is reported as average (standard deviation). } \\
(*) \text { Significance with respect to normal weight subjects of the } \\
\text { control group. } \\
\text { (+) Significance with respect to normal weight subjects of the diet } \\
\text { soft drink consuming group. }\end{array}$} \\
\hline
\end{tabular}

Table 1: General characteristics and difference in anthropometric parameters in schoolchildren evaluated according to nutritional status $(\mathrm{n}=157)$. 
Table 2 shows the nutritional status according to BMI, the daily consumption of glasses of diet soft drinks by the students and the association between these two variables. Regarding the nutritional status of the evaluated students, $42.03 \%$ are classified as normal and $57.97 \%$ present obesity and overweight. Concerning the consumption of diet soft drinks, $35.66 \%$ do not consume this type of drink; $24.84 \%$ consume 1 glass a day and $39.5 \%$ consume between 2 or more glasses a day of diet soft drinks. There was no association between nutritional status according to BMI and the consumption of diet soft drinks by school children ( $p=0.4051)$.

\begin{tabular}{|c|c|c|c|c|}
\hline $\begin{array}{c}\text { Nutrition- } \\
\text { al status }\end{array}$ & Controls & 1 daily glass & $\begin{array}{c}\text { 2 or more daily } \\
\text { glasses }\end{array}$ & Total \\
\hline Normal & $\begin{array}{c}26 \\
(16.56 \%)\end{array}$ & $18(11.46 \%)$ & $22(14.01 \%)$ & $\begin{array}{c}66 \\
(42.03 \%)\end{array}$ \\
\hline Obesity & $\begin{array}{c}30 \\
(19.11 \%)\end{array}$ & $21(13.38 \%)$ & $40(25.48 \%)$ & $\begin{array}{c}91 \\
(57.97 \%)\end{array}$ \\
\hline Total & $\begin{array}{c}56 \\
(35.66 \%)\end{array}$ & $39(24.84 \%)$ & $62(39.50 \%)$ & 157 \\
\hline \multicolumn{5}{|c|}{ Chi-square Test. $\mathrm{p}=0.4051$} \\
\hline
\end{tabular}

Table 2: Nutritional status according to BMI and daily glasses consumed of diet soft drinks in Chilean school children.

According to the waist circumference, $46.49 \%$ are classified without cardiovascular risk, and $53.51 \%$ have risk of abdominal obesity and abdominal obesity. No positive association was observed ( $p=0.7972$ ) between the consumption of diet soft drinks and cardiovascular risk among children (Table 3).

\begin{tabular}{|c|c|c|c|c|}
\hline & Controls & $\begin{array}{c}1 \text { daily } \\
\text { glass }\end{array}$ & $\begin{array}{c}2 \\
\text { or more daily } \\
\text { glasses }\end{array}$ & Total \\
\hline Normal & $\begin{array}{c}28 \\
(17.83 \%)\end{array}$ & $\begin{array}{c}17 \\
(10.83 \%)\end{array}$ & $28(17.83 \%)$ & $73(46.49 \%)$ \\
\hline $\begin{array}{c}\text { Abdominal } \\
\text { obesity }\end{array}$ & $\begin{array}{c}28 \\
(17.83 \%)\end{array}$ & $\begin{array}{c}22 \\
(14.01 \%)\end{array}$ & $34(21.66 \%)$ & $84(53.51 \%)$ \\
\hline Total & $\begin{array}{c}56 \\
(35.66 \%)\end{array}$ & $\begin{array}{c}39 \\
(24.84 \%)\end{array}$ & $62(39.50 \%)$ & 157 \\
\hline \multicolumn{5}{|c|}{ Chi-square Test. $\mathrm{p}=0.7972$} \\
\hline
\end{tabular}

Table 3: Abdominal obesity according to waist circumference and daily glasses consumed of diet soft drinks in Chilean school children.

Figure 1 shows the risk of obesity in school children who never drink diet soft drinks compared to those school children who consume 1 glass a day of diet soft drinks (OR: 1.02 [95\% IC: 0.452.32]). In the case of school children who consume 2 or more glasses a day of diet soft drinks, the risk of obesity could increase by 50\% (OR: 1.52 [95\% IC: 0.74-3.2]), $\mathrm{p}=0.258$ ).

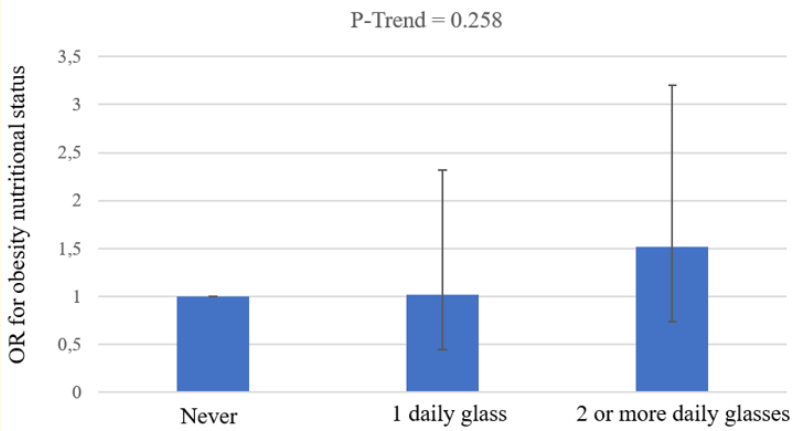

Figure 1: Association between daily consumption of diet soft drinks with obesity.

As can be seen in figure 2, the consumption of 1 daily glass of diet soft drinks could increase the risk of abdominal obesity by 30\% (OR: 1.30 [95\% IC: 0.58-2.98]). The consumption of 2 or more glasses a day also indicates a risk of abdominal obesity in comparison with those children who do not consume diet soft drinks (OR: 1,1 [95\% IC: 0.57-2.4], $\mathrm{p}=0.6726$ ).

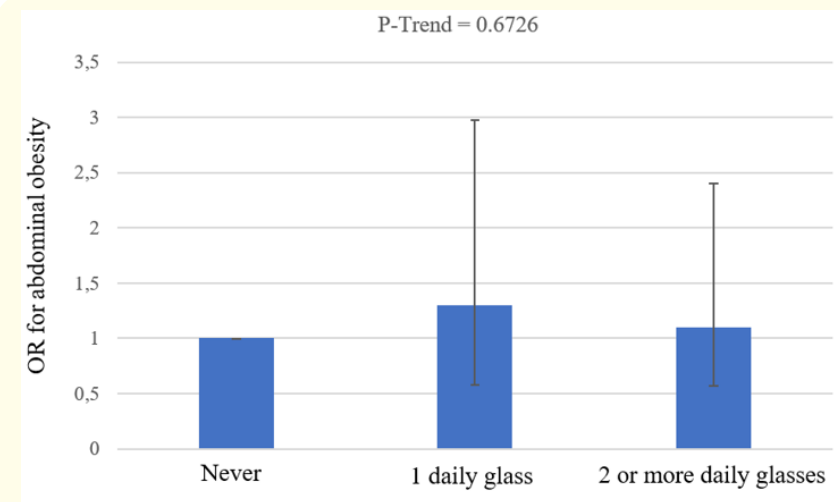

Figure 2: Association between daily consumption of diet soft drinks with abdominal obesity.

In this association study, we studied the relationship between nutritional status and the consumption of diet soft drinks in school children aged 6 to 9 years in Santiago, Chile. This research included the description of the nutritional status, abdominal obesity and consumption of diet soft drinks.

As to the prevalence of malnutrition due to excess found in this research, they are similar to that reported in 2019 by the JUNAEB (National Board of School Aid and Scholarships) where $52 \%$ of Chilean school children are overweight and obese [3]. These results are 
comparable with a study carried out in a public school in Santiago, Chile where the prevalence of overweight and obesity in 8 and 9-year-old school children was $60.1 \%$ [18]. One of the causes that explains this high prevalence of malnutrition due to excess is the decrease in physical activity accompanied by the longest time of use of the computer, television, video games and/or electronic devices such as smartphones and tablets [19]. Other causes involved in the high prevalence of obesity are the increased consumption of processed foods, junk food and foods rich in simple sugars, which are characterized by being foods with a high energy density [20]. The data obtained in this study is worrying due to the nutritional consequences involved, such as the greater risk of chronic noncommunicable diseases, as well as adulthood obesity.

Waist circumference has been shown to be a good predictor of cardiovascular disease and visceral fat [21]. In addition, it has been shown that those with a larger waist circumference are more likely to have diabetes, dyslipidemia, hypertension and metabolic syndrome [22]. In relation to the results of abdominal obesity in this population, the prevalence of abdominal obesity was $31.2 \%$, slightly higher than that found in another study carried out in Chilean school children aged 6 and 7, in which $27.9 \%$ of the children evaluated presented abdominal obesity [23]. The values found in this research are higher than those described in other studies in Chilean school children, where the reported prevalence of abdominal obesity have been $9.6 \%$ and $18.6 \%[24,25]$.

High consumption of artificially sweetened beverages is increasingly common among the school population. Around 64.34\% of the surveyed school children indicated having consumed diet soft drinks, of which $24.84 \%$ drank 1 glass of diet soft drinks a day and $39.5 \%$ drank 2 or more glasses a day of diet soft drinks. These figures are lower than those found in the National Survey of Food Consumption of Chile, where the consumption of soft drinks in children between 6 and 13 years of age was 85.7\% [26]. In the ISCOLE study, whose sample included 6,162 school children between 9 and 11 years of age from 12 countries, $46.7 \%$ of the boys did not consume diet soft drinks, a lower percentage than the $49.3 \%$ amongst the girls. In this same study, 7.1\% of the boys and $5.9 \%$ of the girls drank once a day or more diet soft drinks..$^{27}$ Other data regarding the consumption of this type of beverages was carried out among 2,037 Japanese men in which $79.5 \%$ did not consume or rarely consumed diet soft drinks and $0,98 \%$ consumed 1 or more servings per day [17]. In the study conducted among 6,814 African American, Chinese, Caucasian and Hispanic adults, roughly $14 \%$ of the participants consumed 1 serving of diet soft drinks daily, while $59 \%$ of the participants reported that they never consumed diet soft drinks [29].

Within the objectives of this research, the association between nutritional status, cardiovascular risk and consumption of soft diet drinks was analyzed, observing those school children who consumed 1 or 2 or more glasses of soft diet drinks a day had an increased risk of abdominal obesity, as well as overweight and obesity, in relation to children who did not consume soft diet drinks. This increased risk of obesity was independent of confounding factors such as gender and age.

There are few studies in children that look for this association between soft diet drinks and nutritional status, however, in Fowler., et al. with European-American and Mexican-American older adults, a positive relationship was observed between the increase in waist circumference and the intake of diet soft drinks [30].

In the ARIC study with 9,514 American participants between 45 and 64 years of age, the consumption of diet soft drinks was positively associated with the incidence of metabolic syndrome [31]. In Dhingra., et al. the study of 6,000 adults from the Framingham Heart Study, a significantly higher prevalence of metabolic syndrome was observed in adults who consumed one serving per day of soft diet drinks [32]. In the prospective CARDIA study, young adults who consumed diet beverages had a higher risk of cardiometabolic outcomes [33].

On the impact of the consumption of diet soft drinks and the prevalence of type 2 diabetes, in the meta-analysis developed by Imamura., et al. it was observed that higher consumption of artificially sweetened beverages at a rate of one serving per day was associated with a greater incidence of type 2 diabetes [34]. Other studies have reported similar results on the association between the consumption of diet soft drinks and type 2 diabetes [28,29].

One possible explanation for these findings is that artificially sweetened beverages stimulate the appetite for sweet foods at subsequent meals since the sweeteners used in diet soft drinks are powerful stimulators of sweetness on the palate, which could promote weight gain $[35,36]$. On the other hand, the caramel content in beverages can be a potential source of advanced glycation end products that can promote insulin resistance and could be inflammatory [32].

One of the main strengths of this study was having a sample of school children of both sexes. Another important component to highlight is the standardization in the collection of anthropometric data. The use of a survey designed and validated for this study was another primary advantage.

This study has some limitations which are important to mention. First, due to the cross-sectional nature of this study, causeeffect relationships between the consumption of light soda drinks with obesity and overweight cannot be assumed. In addition, other factors related to overweight and obesity were not considered, such as total dietary intake and level of physical activity, which could influence the risk of obesity. 


\section{Conclusion}

In conclusion, this study reports a high prevalence of malnutrition due to excess in school children, accompanied by a significant percentage of girls and boys who consume soft drinks daily. When dealing with school children, it is important to encourage the consumption of water, for all the benefits that it also has by not providing calories or sugar. It is important to mention that at this age, school children are in a stage of acquisition of eating habits along with the development of the patterns of the compartment on food and nutrition, therefore promoting water consumption is a task that must be carried out. Schools are an appropriate place to promote water consumption, so nutrition education programs should be aimed at promoting water consumption at different meals throughout the day and in physical education classes. These interventions should emphasize a supportive social environment where not only work with the school children, but also with the entire school community, such as parents and teachers. The results of this research suggest that a higher consumption of diet soft drinks plays a fundamental role in the risk of obesity, as well as abdominal obesity. However, more research is needed to include the other factors that influence the prevalence of obesity.

\section{Acknowledgements}

To the students of the School of Nutrition and Dietetics of the Bernardo O'Higgins University for their support in anthropometric measurements and survey applications.

\section{Conflict of Interest}

The Author(s) declare(s) that there is no conflict of interest.

\section{Bibliography}

1. Hales CM., et al. "Prevalence of obesity and severe obesity among adults: United States, 2017-2018” NCHS. Data Brief, no 360. Hyattsville, MD: National Center for Health Statistics (2020).

2. Margozzini P., et al. "National Health Survey, ENS 2016-2017: A contribution to health planning and public policies in Chile". ARS MEDICA Revista de Ciencias Médicas 43 (2018): 30-34.

3. National Board School Aid and Scholarships (JUNAEB). Report Nutritional Map (2019).

4. Williams EP., et al. "Overweight and Obesity: Prevalence, Consequences, and Causes of a Growing Public Health Problem". Current Obesity Reports 4 (2015): 363-370.

5. Llewellyn A., et al. "Childhood obesity as a predictor of morbidity in adulthood: a systematic review and meta-analysis". Obesity Reviews 17 (2016): 56-67.
6. Olson J., et al. "Characterization of Childhood Obesity and Behavioral Factors". Journal of Pediatric Health Care 30 (2016): 444-452.

7. Basu S., et al. "Relationship of Soft Drink Consumption to Global Overweight, Obesity, and Diabetes: A Cross-National Analysis of 75 Countries". American Journal of Public Health 103 (2013): 2071-2077.

8. Tahmassebi JF., et al. "Impact of soft drinks to health and economy: a critical review". European Archives Pediatric Dentistry 21 (2019): 3-11.

9. Malik VS., et al. "Sweeteners and Risk of Obesity and Type 2 Diabetes: The Role of Sugar-Sweetened Beverages". Current Diabetes Reports 12 (2012): 195-203.

10. Crovetto M., et al. "Changes in the consumption of dairy products, sugary drinks and processed juices in the Chilean population". Revista Médica de Chile 142 (2014): 1530-1539.

11. Schulze MB., et al. "Sugar-Sweetened Beverages, Weight Gain, and Incidence of Type 2 Diabetes in Young and Middle-Aged Women". Journal of the American Medical Association 292 (2014): 927-934.

12. Malik VS., et al. "Intake of sugar-sweetened beverages and weight gain: a systematic review". The American Journal of Clinical Nutrition 84 (2006): 274-288.

13. Malik VS., et al. "Sugar-Sweetened Beverages and Risk of Metabolic Syndrome and Type 2 Diabetes". Diabetes Care 33 (2010): 2477-2483.

14. Greenwood DC., et al. "Association between sugar-sweetened and artificially sweetened soft drinks and type 2 diabetes: systematic review and dose - response meta-analysis of prospective studies". British Journal of Nutrition 112 (2014): 725-734.

15. Tate DF., et al. "Replacing caloric beverages with water or diet beverages for weight loss in adults: main results of the Choose Healthy Options Consciously Everyday (CHOICE) randomized clinical trial". The American Journal of Clinical Nutrition 95 (2012): 555-563.

16. National Health and Nutrition Examination Survey (NHANES). "Anthropometry Procedures Manual" (2017).

17. Department of Nutrition and Food of Ministry of Health, Government of Chile. "Growth patterns for nutritional assessment of children and adolescents from birth to 19 years old" (2017). 
18. Rodríguez X., et al. "Assessment of nutritional status and eating habits in 8- and 9-year-old schoolchildren from Santiago de Chile". Revista Española de Nutrición Humana Dietética 23 (2019): 182-247.

19. Arroyo-Johnson C., et al. "Obesity Epidemiology Worldwide”. Gastroenterology Clinics North America 45 (2016): 571-579.

20. Cabrera MA., et al. "Evidence that a tax on sugar sweetened beverages reduces the obesity rate: a meta-analysis". BMC Public Health 13 (2013): 1072-1081.

21. Fernandez JR., et al. "Waist circumference percentiles in nationally representative samples of African-American, European American and Mexican American children and adolescents". The Journal of Pediatrics 145 (2014): 439-444.

22. Ross R., et al. "Waist circumference as a vital sign in clinical practice: a Consensus Statement from the IAS and ICCR Working Group on Visceral Obesity". Nature Reviews Endocrinology 16 (2020): 177189.

23. Rodríguez X. "Healthy eating habits and status nutrition in schoolchildren in Santiago de Chile". Revista Española de Nutrición Comunitaria 24.2 (2018): 1-182.

24. Alarcón M., et al. "Nutritional status and body composition in school children from La Serena, Chile". Revista Chilena de Nutrición 43 (2016): 138-145.

25. Cigarroa I., et al. "Nutritional status, fitness, school performance, anxiety level and health habits in primary school in the Bio Bío province of Chile: A cross-sectional study". Revista Chilena de Nutrición 44 (2017): 209-217.

26. Ministry of Health, Government of Chile. "Food consumption survey in Chile" (2014).

27. Katzmarzyk P., et al. "Relationship between Soft Drink Consumption and Obesity in 9-11 Years Old Children in a Multi-National Study". Nutrients 8 (2016): 770-782.

28. Sakurai M., et al. "Sugar-sweetened beverage and diet soda consumption and the 7-year risk for type 2 diabetes mellitus in middle-aged Japanese men". European Journal of Nutrition 53 (2014): 251-258.

29. Nettleton JA., et al. "Diet Soda Intake and Risk of Incident Metabolic Syndrome and Type 2 Diabetes in the Multi-Ethnic Study of Atherosclerosis (MESA)". Diabetes Care 32 (2009): 688-694.

30. Fowler S., et al. "Diet soda intake is associated with long-term increases in waist circumference in a bi-ethnic cohort of older adults: The San Antonio Longitudinal Study of Aging". Journal of the American Geriatrics Society 63 (2015): 708-715.
31. Lutsey PL., el al. "Dietary Intake and the Development of the Metabolic Syndrome the Atherosclerosis Risk in Communities Study". Circulation 117 (2018): 754-761.

32. Dhingra R., et al. "Soft drink consumption and risk of developing cardiometabolic risk factors and the metabolic Syndrome in Middle-Aged Adults in the Community". Circulation 116 (2007): 480-488.

33. Duffey KJ., et al. "Dietary patterns matter: diet beverages and cardiometabolic risks in the longitudinal Coronary Artery Risk Development in Young Adults (CARDIA) Study". The American Journal of Clinical Nutrition 95 (2012): 909-915.

34. Imamura F., et al. "Consumption of sugar sweetened beverages, artificially sweetened beverages, and fruit juice and incidence of type 2 diabetes: systematic review, meta-analysis, and estimation of population attributable fraction". British Medical Journal 21 (2015): h3576.

35. De Koning L., et al. "Sugar sweetened and artificially sweetened beverage consumption and risk of type 2 diabetes in men". The American Journal of Clinical Nutrition 93 (2011): 1321-1327.

36. Pereira MA. "Sugar-Sweetened and Artificially-Sweetened Beverages in Relation to Obesity Risk". Advances in Nutrition 5 (2014): 797-808.

\section{Assets from publication with us}

- Prompt Acknowledgement after receiving the article

- Thorough Double blinded peer review

- Rapid Publication

- Issue of Publication Certificate

- High visibility of your Published work

Website: www.actascientific.com/

Submit Article: www.actascientific.com/submission.php Email us: editor@actascientific.com

Contact us: +919182824667 